\title{
MONOARTRITE E POLIARTRITE AGUDA
}

\author{
ACUTE MONOARTHRITIS AND ACUTE POLYARTHRITIS
}

Rogério Carvalho Vieira Chachá1 \& Paulo Louzada Jr²

${ }^{1}$ Pós-graduando ${ }^{2}$ Docente. Divisão de Imunologia Clínica. Departamento de Clínica Médica. Faculdade de Medicina de Ribeirão Preto - USP. CorRESPONDÊNCIA: Paulo Louzada Jr. Divisão de Imunologia Clínica. Departamento de Clínica Médica. Faculdade de Medicina de Ribeirão Preto- USP. Campus de Ribeirão Preto - USP. Av. Bandeirantes, 3900. CEP 14.048-900 Ribeirão Preto - SP - Brasil. Fone : (16) 6022566 - Fax: (16) 633 6695. E-mail: plouzada@fmrp.usp.br

CHACHÁ RCV \& LOUZADA Jr P. Monoartrite e poliartrite aguda. Medicina, Ribeirão Preto, 36: 418-426, abr./dez.2003.

RESUMO - Diversas doenças, principalmente não reumáticas, manifestam-se com artrite aguda. O padrão monoarticular é característico da gota e da artrite séptica. Poliartrite aguda predomina nas doenças infecciosas. A abordagem das artrites agudas exige cuidadosa história clínica e exame físico completo. A punção articular deve sempre ser realizada nos quadros de artrite aguda, para obtenção do líqüido sinovial. A análise e a cultura do fluido são exames importantes para o auxílio diagnóstico.

UNITERMOS - Artrite. Artrite Infecciosa. Gota.

\section{1- INTRODUÇÃO}

O objetivo principal da avaliação clínica de um paciente com manifestações reumáticas é identificar sinais e sintomas que permitam distinguir os sintomas em três categorias: inflamatória, degenerativa-metabólica e funcional (psicogênica), as quais estão representadas na Tabela I.

\section{2- MONOARTRITE AGUDA}

Diversas afecções podem se apresentar desta forma. São exemplos a artrite traumática, a hemorrágica, a séptica e a gota. Na primeira, o fator desencadeante é o trauma, a radiografia faz parte da avaliação pela possibilidade de fratura. Em geral, há necessidade de cuidados ortopédicos. Suspeita-se de artrite hemorrágica, quando o paciente é portador de alguma discrasia sangüínea e a punção articular, com obtenção do líquiido sinovial, é diagnóstica. O tratamento é dirigido à doença hematológica. As duas últi- mas condições se constituem em maior desafio para o clínico serão abordadas em maior detalhe.

\section{1- Gota}

\subsection{1- Introdução e epidemiologia}

Gota diz respeito a um grupo heterogêneo de doenças, que resultam da deposição tecidual de urato monossódico ou de cristais de urato. As manifestações clínicas da deposição incluem crises recorrentes de artrite aguda (gota aguda ou crise aguda); acúmulo de agregados de cristais potencialmente destrutivos (tofos); urolitíase e, menos freqüentemente, deterioração da função renal (nefropatia gotosa). A hiperuricemia é o denominador patológico comum.

A epidemiologia da gota tem mudado ao longo dos anos. A proporção de homens: mulheres que já foi de 20:1 é de 2 a 7:1, segundo alguns estudos recentes. Tal fato explica-se, possivelmente, pela crescente mudança de hábitos da população feminina para entrar e permanecer no mercado de trabalho. 
Tabela I: Sinais e sintomas úteis no diagnóstico diferencial das artrites

\begin{tabular}{|c|c|c|c|}
\hline Sintomas & Degenerativa & Inflamatória & Psicogênica \\
\hline Rigidez articular (duração) & Alguns minutos & Horas; mais acentuada após repouso & $\begin{array}{l}\text { Pouca ou nenhuma variação com o } \\
\text { repouso ou com a atividade }\end{array}$ \\
\hline Dor & $\begin{array}{l}\text { Piora com atividade e melhora } \\
\text { com repouso }\end{array}$ & $\begin{array}{l}\text { Mesmo em repouso; a dor noturna } \\
\text { pode interferir com o sono }\end{array}$ & $\begin{array}{l}\text { Pouca ou nenhuma variação com o } \\
\text { repouso ou com a atividade }\end{array}$ \\
\hline Fraqueza & Incomum & Freqüentemente acentuada & Queixa frequiente \\
\hline Fadiga & Incomum & $\begin{array}{l}\text { Freqüiente, especialmente no início da } \\
\text { tarde }\end{array}$ & Freqüente, especialmente ao acordar \\
\hline $\begin{array}{l}\text { Labilidade emocional e } \\
\text { depressão }\end{array}$ & Incomum & $\begin{array}{l}\text { Comum; coincide com a fadiga, } \\
\text { freqüentemente desaparece com a } \\
\text { remissão da doença }\end{array}$ & Freqüente \\
\hline \multicolumn{4}{|l|}{ Sinais } \\
\hline $\begin{array}{l}\text { Dor localizada sobre as } \\
\text { articulações afetadas }\end{array}$ & Comum & Sempre presente & $\begin{array}{l}\text { Dor difusa ("dói tudo"); tendência a } \\
\text { empurrar ou a segurar a mão do } \\
\text { examinador. }\end{array}$ \\
\hline Edema & $\begin{array}{l}\text { Efusão é comum; pouca reação } \\
\text { sinovial }\end{array}$ & $\begin{array}{l}\text { Efusão é comum; espessamento } \\
\text { sinovial é freqüente }\end{array}$ & Ausência \\
\hline Calor e eritema na pele & Incomum & Comum & Ausência \\
\hline Crepitações & Grosseiras e médias & Médias e finas & Ausência \\
\hline \multirow[t]{14}{*}{ Esporões ósseos } & Comuns & Em associação com osteoartrite & Ausência \\
\hline & \multicolumn{3}{|c|}{ Exemplos de doenças } \\
\hline & Não inflamatórias & Inflamatórias & Funcionais \\
\hline & Osteoartrite & Artrite reumatóide & Fibromialgia \\
\hline & Trauma & Tenossinovite cálcica & Histeria \\
\hline & Artropatia metabólica & Poliartrites soronegativas & \\
\hline & $\begin{array}{l}\text { Anormalidades mecânicas } \\
\text { (menisco, lesão ligamentar). }\end{array}$ & Lúpus eritematoso sistêmico & \\
\hline & Distrofia simpaticoreflexa & Outras colagenoses & \\
\hline & $\begin{array}{l}\text { Tumores (sinovite vilonodular } \\
\text { pigmentada) }\end{array}$ & Espondiloartropatias soronegativas & \\
\hline & Discrasias sangüíneas (hemofilia) & Artrite crônica juvenil & \\
\hline & Tendinites & Doença por deposição de microcristais & \\
\hline & Ósteonecrose asséptica & $\begin{array}{l}\text { Artrites virais (rubéola, sarampo, } \\
\text { parvovírus, hepatite B). }\end{array}$ & \\
\hline & & $\begin{array}{l}\text { Artrites infecciosas (bacteriana, } \\
\text { fúngicas, tuberculosa). }\end{array}$ & \\
\hline & & $\begin{array}{l}\text { Artrites por imunocomplexos } \\
\text { (crioglobulina, endocardite bacteriana). }\end{array}$ & \\
\hline
\end{tabular}




\subsection{2- Patogênese}

A hiperuricemia exerce papel central no desenvolvimento da gota e, por esse motivo, sempre se deve tentar identificar fatores que elevem as concentrações de ácido úrico no organismo, o que pode ocorrer através de dois mecanismos: redução da excreção e aumento da produção de urato.

As condições que levam ao desbalanço da concentração endógena da substância estão listadas nas Tabelas II e III.

As drogas mais corriqueiras na prática médica, que elevam os níveis séricos de ácido úrico, são listadas na Tabela IV. Quando houver viabilidade, sua substituição trará benefícios ao doente gotoso.

Dentre os fatores causais citados, o álcool tem grande importância já que interfere nos dois processos e seu uso é disseminado na população.

Além de tais medicações, o uso de uricosúricos, ou inibidores da síntese do ácido úrico, também pode desencadear crises de gota por mecanismo diverso. Tais drogas ocasionam redução do nível sérico do ácido úrico, há mobilização de depósitos teciduais, o que poderá culminar com nova precipitação.

\subsection{3- Quadro clínico}

O evento inicial da gota é a crise aguda, cujas características estão sumarizadas na Tabela V. As crises, em geral, acontecem à noite ou durante a madrugada e as articulações preferencialmente acometidas são as de membros inferiores. Isso se justifica pela redução da solubilidade e maior precipitação do urato com o frio.

Pode-se perceber, além da dor e do edema articulares, vermelhidão e calor da pele subjacente.

O curso clínico é variável, e as queixas podem durar de horas a semanas. As crises de gota aguda podem ocorrer na ausência de hiperuricemia.

\subsection{4- Diagnóstico}

O diagnóstico deve ser suspeitado na população sob risco, levando-se em conta idade, sexo, clínica, comorbidades, hábitos e uso de drogas. Pode ainda ser definitivo ou provável.

\begin{tabular}{|c|c|}
\hline Nutricional & $\begin{array}{l}\text { Álcool } \\
\text { Obesidade }\end{array}$ \\
\hline Renal/vascular & $\begin{array}{l}\text { Doença renal } \\
\text { Hipertensão }\end{array}$ \\
\hline Drogas & Tabela IV \\
\hline Metabólicos/hormônios & $\begin{array}{l}\text { Acidose lática } \\
\text { Cetose (jejum, diabetes). } \\
\text { Vasopressina } \\
\text { Angiotensina }\end{array}$ \\
\hline Outros & $\begin{array}{l}\text { Mixedema } \\
\text { Acidose respiratória } \\
\text { Infarto agudo do miocárdio }\end{array}$ \\
\hline
\end{tabular}

Tabela IV - Drogas que interferem na homeostase do urato

\section{Redução da excreção}

Aspirina (baixa dose) Fenilbutazona (baixa dose)

Diuréticos tiazídicos Furosemide

Etambutol Pirazinamida

Aumento da produção

Citotóxicas Warfarin

Ciclosporina Ácido nicotínico 


\begin{tabular}{|c|c|c|}
\hline & Homens & Mulheres \\
\hline Idade & 30 a 50 anos & 50 a 70 anos (pós-menopausa) \\
\hline $\begin{array}{l}\text { Padrão } \\
\text { articular }\end{array}$ & $\begin{array}{l}\text { Monoarticular }(80 \%) \\
1^{\text {a'MTF* }}(50 \%)\end{array}$ & Poliarticular \\
\hline
\end{tabular}

A radiografia pode ser solicitada na crise aguda, quando sua principal finalidade é diferenciá-la de outras condições patológicas. As demais alterações são colocadas na Tabela VII.

\subsection{7- Tratamento}

A terapia, na gota, é dirigida, primariamente, à crise aguda e, secundariamente, à correção da hiperuricemia, causa básica das crises. Há três possibilidades efetivas para o tratamento da crise

1. Definitivo - demonstração do cristal de urato no interior de neutrófilos do líquiido sinovial, sendo a pesquisa realizada com microscópio de luz polarizada. O líqüido sinovial é inflamatório, não purulento, ou seja, há entre 3000 e 50000 leucócitos, a maioria polimorfonucleares ( $70 \%$ ou mais), e a cultura é negativa.

2. Provável - combinação das três condições abaixo

a. História de monoartrite episódica, intercalada com períodos totalmente assintomáticos;

b. Resolução rápida com o uso de colchicina

c. Hiperuricemia.

\subsection{5- Diagnóstico diferencial}

O diagnóstico diferencial mais importante, no caso de monoartrite, é com artrite séptica, pois esta pode levar rapidamente a seqüelas articulares irreversíveis. Sempre que houver derrame articular e mínima dúvida diagnóstica, deve-se solicitar a análise e, principalmente, a cultura do líquiido sinovial.

Outras doenças por depósito de cristal podem simular a gota. Exemplo disso é a pseudogota, deposição de cristal de pirofosfato de cálcio (CPPD). As diferenças entre as duas entidades figuram na Tabela VI.

\subsection{6- Laboratório}

O principal exame para diagnóstico da gota é a análise do líquiido sinovial. Há leucocitose e elevação da velocidade de hemossedimentação (VHS), na crise aguda. aguda de gota: (i) colchicina, (ii) antiinflamatórios não hormonais (AINE) e (iii) corticóides.

A colchicina tem ação antiinflamatória e efeito profilático, evitando a recorrência das crises. É a medicação clássica para o tratamento da gota aguda e, atualmente, usada em associação aos AINE, respeitadas as contra-indicações deles (insuficiência renal, hipertensão arterial, doença ulcerosa péptica, cirrose hepática). A apresentação disponível é em comprimidos de 0,5 mg. Uma das opções de posologia é 1 comprimido de 6 em $6 \mathrm{~h}$ por 3 dias, com redução progressiva da dose para $8 \mathrm{em} 8 \mathrm{~h}$ por mais 3 dias e, a seguir, $12 \mathrm{em} 12 \mathrm{~h}$. A dose profilática média é de 2 comprimidos ao dia. Os principais efeitos colaterais são gastrointestinais: diarréia, náuseas e vômitos, reversíveis à redução ou suspensão da droga.
Tabela VI - Comparação entre gota e pseudogota

\begin{tabular}{l|l|l} 
& Gota & Pseudogota \\
\hline Razão M:F & $2-7: 1$ & $1: 2$ \\
\hline Pico de incidência & $40-50$ & $>60$ \\
\hline Articulação mais afetada & $1^{\text {a }}$ metatarsofalangeana & Joelho \\
\hline Ácido úrico sérico & Alto & Normal \\
\hline $\begin{array}{l}\text { Radiografia } \\
\text { Calcificação } \\
\text { Erosão }\end{array}$ & $\begin{array}{l}\text { Ausente } \\
\text { Paramarginal }\end{array}$ & $\begin{array}{l}\text { Condrocalcinose } \\
\text { Padrão } \\
\text { degenerativo }\end{array}$ \\
\hline
\end{tabular}

Tabela VII - Alterações radiográficas na gota

Primeira crise Sem alteração

Doença Ausência de osteopenia periarticular

crônica $\quad$ Espaço articular preservado

Cistos e erosões paramarginais, com esclerose ao redor 
Alguns antiinflamatórios estão na Tabela VIII. As doses iniciais, utilizadas na crise de gota são maiores que as de uso rotineiro. A quantidade é gradualmente reduzida e mantida até um ou dois dias após a dor ter cessado.

No caso de dor muito intensa, pode-se utilizar as formas injetáveis dos antiinflamatórios, como primeira administração. O diclofenaco pode ser aplicado IM, $75 \mathrm{mg}$, uma vez por dia, ou, então, o cetoprofeno, 100mg, endovenoso, diluído em $100 \mathrm{ml}$ de solução fisiológica, até três vezes ao dia. O uso de AINH injetável não deve ultrapassar dois dias. Estudos têm mostrado eficácia comparável dos AINE inibidores seletivos de COX-2 aos citados na Tabela com menor incidência de efeitos colaterais gastrointestinais. Pode-se utilizar Celecoxibe, 200mg, 2 vezes ao dia; Rofecoxibe, $50 \mathrm{mg}$ ao dia ou Etoricoxibe, $120 \mathrm{mg}$ ao dia.

A administração de corticóides para o tratamento da gota pode ser feita de duas formas: intra-articular ou via oral. A primeira forma é particularmente útil, quando os sintomas são monoarticulares, há mau funcionamento renal ou outras condições que contraindiquem o uso de AINE. A resolução dos sintomas costuma ser rápida não só pela droga usada, mas, também, pela aspiração e drenagem do derrame articular. Ao se fazer a opção pela via oral, inicia-se com $0,5 \mathrm{mg} / \mathrm{kg}$ de prednisona, com redução gradual em 10 dias.

A identificação de fatores predisponentes à hiperuricemia é importante nesta fase, para planejamento do tratamento futuro.

\section{2- Artrite Séptica Não Gonocócica}

O diagnóstico de artrite séptica permanece desafiador para o clínico tal qual há 20 anos. O prognóstico do paciente, hoje, é o mesmo que naquela época, apesar dos grandes avanços na antibioticoterapia e técnicas de diagnóstico por imagem.

Há maior incidência de artrite séptica nos indivíduos com doença articular prévia (por exemplo, artrite reumatóide) ou que sofreram cirurgia articular e nos idosos. Quaisquer situações que causem imunodepressão também levam a aumento do risco: insuficiência renal crônica, transplante, uso de drogas imunossupressoras.

O fator prognóstico de maior importância é a velocidade com que o diagnóstico é realizado e os antibióticos instituídos. A demora levará a seqüelas irreversíveis em poucos dias.

\subsection{1- Quadro clínico}

Monoartrite aguda é a regra, mas cerca de $20 \%$ dos casos de artrite séptica são oligo ou poliarticulares. As grandes articulações são mais comumente envolvidas; em ordem decrescente de freqüência: joelho, quadril, tornozelo, ombro, punho, cotovelo e pequenas articulações das mãos. Os clássicos achados de síndrome infecciosa (febre e leucocitose) podem não estar presentes, principalmente nos indivíduos imunodeprimidos e nos idosos.

\subsection{2- Diagnóstico}

O elevado índice de suspeição continua sendo a ferramenta diagnóstica mais importante.

Quando a hipótese de artrite séptica é considerada, deve-se obter líquiido sinovial para cultura e citologia. A cultura é o padrão ouro para diagnóstico de artrite séptica, com cerca de $90 \%$ de positividade. O patógeno mais implicado é o Staphilococcus aureus, mas a incidência de gram-negativos tem aumentado.

A análise citológica do líqüido revela contagens de leucócitos acima de 50000/ $/ \mathrm{mm}^{3} \mathrm{em} \mathrm{70 \%} \mathrm{dos} \mathrm{indiví-}$ duos com predomínio de polimorfonucleares. Tal resultado indica a introdução de antibioticoterapia até o resultado da cultura. Quando o número de leucócitos é menor que $50000 / \mathrm{mm}^{3}$, a cultura deve ser aguardada.

\subsection{3- Tratamento}

A escolha empírica recai sobre drogas que atuem contra o principal agente: Staphilococcus aureus. Institui-se Oxacilina $2 \mathrm{~g}$ a cada $6 \mathrm{~h}$ por via endovenosa em associação a Gentamicina 3-5mg/kg/dia, quando houver comorbidades ou imunodepressão. Baseadas na cultura do líquiido e antibiograma, podem ser realizadas as alterações necessárias no esquema antibiótico inicial. O tempo de uso dos antibióticos é de, pelo menos, 3 semanas. Existe consenso de que a drenagem articu- 
lar deve ser sempre realizada. Adúvida permanece quanto ao modo: cirúrgico (aberto) ou punção seriada. Algumas indicações da drenagem cirúrgica são: articulação profunda, extensão extra-articular da infecção, diagnóstico tardio com presença de aderências e articulação já doente (por exemplo, artrite reumatóide).

\section{3- POLIARTRITE AGUDA}

Poliartrite aguda é um padrão de acometimento articular, associado a diversas doenças não reumáticas. Aguda pressupõe tempo de manifestação menor que 6 semanas. A cronicidade (mais de 6 semanas) é um aspecto primordial para se estabelecer o diagnóstico de afecção reumática, o que demandará tratamento prolongado. A princípio, todas as doenças reumáticas crônicas (artrite reumatóide, lúpus eritematoso sistêmico, espondiloartropatias soronegativas, artrite crônica, juvenil, entre outras) irão ter uma fase de apresentação aguda. Em relação à etiologia, a poliartrite aguda pode ser secundária a processos infecciosos, a doenças reumáticas e a doenças linfoproliferativas. Na Tabela IX, são resumidas as principais etiologias de poliartrite aguda.

\section{Tabela IX - Diagnóstico diferencial em poliartrite aguda}

\begin{tabular}{|l|l} 
Doenças & Características \\
\hline Febre reumática & $\begin{array}{l}\text { - Primeiro surto em crianças. Poliartrite migratória e febre. } \\
\text { - Cardite, coréia, nódulos subcutâneos e eritema marginado. } \\
\text { - Infecção estreptocócica, pregressa, comumente assintomática. Deve-se obter } \\
\text { evidência sorológica (ASO com títulos ascendentes). }\end{array}$ \\
\hline Espondiloartropatias soronegativas & $\begin{array}{l}\text { - Síndrome de Reiter: promiscuidade sexual ou homossexual, masculina, com } \\
\text { uretrite; irite; conjuntivite; diarréia; balanite circinada; ceratoderma blenorrágico; } \\
\text { envolvimento articular, periférico, assimétrico; sacroileíte assimétrica, com } \\
\text { envolvimento descontínuo da coluna vertebral e sindesmófitos assimétricos. A } \\
\text { síndrome pode ser incompleta e afetar mulheres. }\end{array}$
\end{tabular}

Artrite gonocócica

- Artrite migratória ou tenossinovite, que, finalmente, se estabelecem em uma ou mais articulações; foco primário pode ser uretra, trato genitourinário feminino, reto, orofaringe; lesões cutâneas do tipo pústula; culturas positivas no sítio primário, no sangue ou no líquiido sinovial.

Artrite meningocócica

- Poliartrite simétrica, aditiva, geralmente, associada a meningococcemia e meningite.

- Líqüido sinovial estéril.

\section{- Rubéola e parvovírus B19}

Mulheres jovens com poliartrite aguda. Envolvimento semelhante ao da artrite reumatóide, porém autolimitado. Líquiido sinovial é não inflamatório.

\section{- Vírus B da hepatite}

Infecções virais Poliartrite freqüentemente acompanhada de erupção urticariforme e tenossinovite na fase pré-ictérica. Líqüido sinovial não inflamatório.

\section{- HIV}

Artralgia é mais comum, mas oligoartrite aguda ou poliartrite persistente podem ocorrer. O derrame articular também é não inflamatório. Levando-se em conta os fatores de risco, tais pacientes são mais predispostos a outras doenças, como infecção gonocócica, artrite séptica, síndrome de Reiter, artrite psoriática. Nessas condições, o quadro articular passa a ser relativo a essas doenças.

Endocardite bacteriana

Leucemia aguda
- Artralgia mais comum que artrite. Líquiido sinovial costuma ser estéril

- Febre, aparecimento de sopros cardíacos, esplenomegalia.

- Hemoculturas positivas e visualização de vegetações no ecocardiograma. 
Para a definição da etiologia da poliartrite aguda, deve-se dar grande importância à história clínica e a achados de exame físico em outros aparelhos. As pistas mais importantes para o diagnóstico final surgirão do uso das duas ferramentas.

A poliartrite, observada na Febre Reumática, é, geralmente, migratória, preferencialmente, iniciando-se nos membros inferiores e em grandes articulações. Posteriormente, acomete membros superiores, durando poucos dias, migrando, em seguida, para outra articulação. De forma geral, sua duração é de, no máximo, 3 semanas, na ausência de tratamento com antiinflamatórios não esteroidais. O envolvimento pode, às vezes, ser oligoarticular e acometer a articulação temporomandibular. Está presente em $75 \%$ dos pacientes com febre reumática. Se os pacientes apresentarem, inicialmente, poliartrite, $26 \%$ desenvolvem cardite; porém, se o acometimento articular inicial foi artralgia, 96\% deles podem desenvolver cardite.

A síndrome de Reiter pode cursar com artrite, tenossinovite, conjuntivite e uretrite (ou diarréia). Além disso, outras manifestações clínicas incluem lesões cutaneomucosas, características (balanite circinada e ceratoderma blenorrágica), uveíte, entesite, úlceras orais e lombalgia de caráter inflamatório com sacroileíte na radiografia de bacia. O principal agente da síndrome de Reiter é a Chlamydia trachomatis, cuja porta de entrada é o trato genitourinário. Também são agentes deflagradores da doença Yersinia, Salmonella, Shigella, Campylobacter; nesse caso, a infecção se faz pelo tubo gastrointestinal. O quadro articular, geralmente, é uma oligoartrite assimétrica, de membros inferiores, com dor lombar baixa, inflamatória, unilateral (devido à sacroileíte). Por vezes, pode ocorrer dactilite associada, caracterizando uma poliartrite aditiva, porém assimétrica.

Em relação às doenças sexualmente transmissíveis (DST), os fatores de risco semelhantes, na aquisição de tais infecções, e algumas manifestações clínicas tornam as DST parte do diagnóstico diferencial de uma poliartrite aguda. Testes para HIV, sífilis e Chlamydia são apropriados na suspeita de uma poliartrite aguda, secundária a contato sexual, não protegido. A síndrome de Reiter deve ser sempre considerada, na suspeita de DST, pois o agente patogênico mais comumente identificado na síndrome é a Chlamydia. A infecção gonocócica, disseminada (IGD) será tratada com detalhe no item 3. Um diagnóstico difícil é diferenciar a infecção gonocócica, disseminada da infecção meningocócica, especialmente no que se refere ao acometimento articular. As manifestações articulares e dermatológicas da infecção meningocócica, disseminada são virtualmente indistinguíveis daquelas observadas na IGD. A artrite ocorre em 2 a 10\% dos pacientes com infecção meningocócica aguda. Há três tipos de acometimento articular; (1) poliartrite aguda, associada a meningococcemia aguda e meningite; (2) monoartrite ou oligoartrite que se inicia 5 a 7 dias após a septicemia; (3) artrite piogênica, primária, não associada a meningococcemia ou meningite. Invasão direta da sinóvia e isolamento da $N$. meningitis, a partir de cultura do líquiido sinovial, são mais comuns nos casos de artrite meningocócica, crônica, primária. Na maioria dos casos, a poliartrite aguda, associada a meningococcemia, possui líqüido sinovial estéril. Artrite pós-infecciosa, ou mediada por imunocomplexos, tem sido postulada como possível patogênese. O clássico purpuromeningocócico associado a meningococcemia pode estar presente, mas a dermatite se assemelha a observada na IGD. Tenossinovites são comuns, especialmente associadas à poliartrite aguda.

Os sintomas articulares, observados na rubéola, são comuns em adultos, especialmente na mulher, ocorrendo uma semana antes ou uma semana depois do início da erupção cutânea. Pode ser migratório, com duração de poucos dias até duas semanas. Artralgia é mais comum que artrite. Porém, pode ocorrer poliartrite, semelhante à observada na artrite reumatóide. Tais quadros podem ocorrer, também, após vacinação com vírus atenuado, anti-rubéola. Na artropatia associada à infecção pelo parvovírus B19, o quadro de poliartrite simétrica, de pequenas e grandes articulações pode ocorrer, sendo que, inclusive, pode tornarse crônico.

Artralgias são as manifestações reumáticas mais comumente associadas à infecção pelo HIV. Elas podem ocorrer em qualquer estágio da infecção (12 a $45 \%$ dos pacientes apresentam queixas articulares), sendo de intensidade leve a moderada, transitórias ou intermitentes e, geralmente, oligoarticulares. Grandes articulações como joelhos, tornozelos e ombros são mais comumente afetados. As manifestações reumáticas, descritas na infecção pelo HIV estão resumidas na Tabela IX.

Na Hepatite B, geralmente, ocorre uma poliartrite simétrica, com envolvimento das articulações das mãos, joelhos, punhos, tornozelos, cotovelos e ombros. A rigidez matinal é comum. A artrite pode preceder a icterícia por dias a semanas, freqüentemente desaparecen- 
do após o início da icterícia. Pacientes com hepatite B, crônica, ativa podem apresentar episódios recorrentes de artralgia e artrite. As características do envolvimento articular estão resumidas na Tabela IX.

A Endocardite bacteriana também deve ser lembrada. O quadro mais freqüente é o de poliartralgia, mas poliartrite simétrica e aditiva pode ocorrer. $\mathrm{O}$ líqüido sinovial, freqüentemente, é estéril.

A artrite séptica, na minoria dos indivíduos, pode ter apresentação poliarticular e foi tratada separadamente. Outra entidade que cursa com poliartrite aguda é a doença gonocócica.

\section{1- Artrite Gonocócica}

Há tendência atual de englobar a artrite gonocócica como parte da infecção gonocócica, disseminada (IGD), já que outros sinais e sintomas são prevalentes à artrite.

Apesar da redução do número de casos nas últimas décadas, a artrite gonocócica ainda é a forma mais comum de artrite séptica nos indivíduos sexualmente ativos.

\subsection{1- Quadro clínico}

A IGD se desenvolve após infecções de mucosas não tratadas, mas apenas $25 \%$ dos indivíduos se lembram de uretrite ou cervicite pregressa.

$\mathrm{O}$ desenvolvimento da doença acontece de um dia a algumas semanas depois do contato sexual. Os sintomas mais comuns são poliartralgias migratórias, tenossinovite, dermatite e febre (Tabela X).

A tenossinovite é um sinal importante e distingue a entidade dos outros tipos de artrite séptica. Os

\begin{tabular}{|l|c|}
$\begin{array}{l}\text { Tabela X - Sintomas e sinais } \\
\text { gonocócica disseminada }\end{array}$ & $\begin{array}{c}\text { Percentagem de } \\
\text { pacientes }\end{array}$ \\
\hline \multicolumn{1}{|c|}{ Sintomas e sinais } & 70 \\
\hline Poliartralgia migratória & 67 \\
\hline Tenossinovite & 55 \\
\hline Dermatite & 55 \\
\hline Febre & 55 \\
\hline Artrite purulenta & 20 \\
\hline $\begin{array}{l}\text { Monoartrite } \\
\text { Poliartrite }\end{array}$ & 35 \\
\hline Sintomas genitourinários & 25 \\
\hline
\end{tabular}

locais mais freqüentes de aparecimento são o dorso do punho, quirodáctilos, tornozelos e pododáctilos. A presença concomitante de dermatite aumenta muito o grau de suspeição da doença.

As lesões dermatológicas elementares mais comuns são as pápulas ou máculas hemorrágicas, mas pústulas, vesículas, eritema nodoso ou eritema multiforme também podem ocorrer. São freqüentemente múltiplas e distribuem-se principalmente, nas extremidades e tronco, poupando rosto, palmas e plantas.

Artrite purulenta está presente em cerca de $55 \%$ dos doentes. Na maior parte das vezes, o acometimento é poliarticular e estão envolvidos mais comumente os joelhos, punhos e tornozelos.

\subsection{2- Diagnóstico}

A suspeita baseada nos indícios clínicos é o maior aliado do médico.

O diagnóstico definitivo é realizado com a identificação do germe pela coloração de Gram (diplococo intracelular Gram-negativo) ou cultura.

O líqüido sinovial deve ser obtido sempre que possível. O derrame articular costuma ser menor que nas artrites sépticas. A contagem de leucócitos varia entre 30 e $100 \mathrm{mil} / \mathrm{mm} 3$, com predomínio de polimorfonucleares. Com o uso da coloração de Gram, a bactéria pode ser vista em cerca de $25 \%$ dos doentes. Já a cultura do fluido apresenta positividade entre 30 e $60 \%$.

A obtenção de outras secreções é imperativa para confirmação da hipótese clínica. No homem, o swab uretral, pois a maioria não tem corrimento. $\mathrm{Na}$ mulher, a amostra é do cérvix uterino. Além destas, swab de orofaringe e retal. As culturas do trato genitourinário mostram positividade de 70 a $86 \%$.

Os fluidos obtidos de sítios estéreis devem ser semeados imediatamente em ágar-chocolate e incubados à temperatura de $34 \mathrm{a} 37^{\circ} \mathrm{C}$ de preferência, em ambiente com 5\% de $\mathrm{CO}_{2}$. Para as demais amostras, a incubação deve ser realizada em meios seletivos, como o de Thayer-Martin, Martin-Lewis ou de New York. Caso os procedimentos não sejam realizados, o índice de positividade se reduz drasticamente.

Outra possibilidade é a detecção do agente através de PCR (polimerase chain reaction).

\subsection{3- Tratamento}

O paciente deve ser internado e o esquema antibiótico figura na Tabela XI. Os derrames articulares devem ser drenados por punção seriada. Raramente, há necessidade de drenagem cirúrgica. 
Tabela XI - Tratamento antibiótico empírico na infecção gonocócica, disseminada

Fase hospitalar

Primeira opção Ceftriaxona 1g 12/12h endovenoso

Gravidez Ceftriaxona

Alergia a penicilina
Espectinomicina $2 \mathrm{~g} 12 / 12 \mathrm{~h}$ intramuscular
$\mathrm{Na}$ alta

Ciprofloxacino 500mg 12/12h via oral

Amoxacilina-500mg- Clavulanato

$125 \mathrm{mg}$ via oral $8 / 8 \mathrm{~h}$ ou

Cefuroxima 500mg 12/12h
A alta pode ser dada $24 \mathrm{~h}$ após a melhora clínica. Mantém-se o tratamento via oral, em casa, por mais uma semana. Se estiver disponível a cultura e o antibiograma são realizadas trocas com maior segurança.

A infecção concomitante por Chlamydia não é incomum e, a menos que testes apropriados para detecção da bactéria sejam negativos, o tratamento é instituído. Usa-se Doxiciclina 100mg de 12 em 12 h por via oral e, na gravidez, Eritromicina 500mg, 4 vezes ao dia, por via oral.

CHACHÁ RCV \& LOUZADA Jr P. Acute monoarthritis and acute polyarthritis. Medicina, Ribeirão Preto, 36: 418-426, apr./dec. 2003.

ABSTRACT - Several diseases, particularly non rheumatic, may present with acute arthritis. Gout and septic arthritis are typically monoarticular. The acute polyarticular pattern predominates in infectious diseases. Careful clinic history and physical examination are essential to the correct diagnosis of acute arthritis. Arthrocentesis is required to evaluate fully a patient with acute arthritis. The synovial fluid should be analyzed (routine synovianalysis) and cultured to perform a correct diagnosis.

UNITERMS - Arthritis. Arthritis, Infectious. Gout.

\section{BIBLIOGRAFIA RECOMENDADA}

1 - EMMERSON BT. The management of gout. $\mathbf{N}$ Engl $\mathbf{J}$ Med. 334: 445-451, 1996.

2 - KLIPPEL JH \& DIEPPE PA, eds. Rheumatology. 2th ed, Mosby, London, 1998.
3 - KOOPMAN WJ, ed. Arthritis and allied conditions. $14^{\text {th }}$ ed, Lippincott Williams \& Wilkins, Philadelphia, 2001.

4 - WEST SG, ed. Rheumatology secrets. Hanley \& Belfus, Philadelphia, 1997. 